\title{
ULTRASONIC DIAGNOSIS OF NEONATAL SEPARATION OF THE DISTAL HUMERAL EPIPHYSIS
}

\author{
J. J. DIAS, A. C. LAMONT, J. M. JONES
}

From Leicester General Hospital and Royal Infirmary

\begin{abstract}
We report a case of neonatal separation of the distal humeral epiphysis in which non-invasive ultrasonic examination provided clear definition of the injury.
\end{abstract}

Traumatic separation of the distal epiphysis of the humerus at birth is a rare injury and very few cases have been reported (Siffert 1963; Ekengren, Bergdahl and Ekström 1978). Before the appearance of the ossification centre of the capitellum at three to nine months (Rogers and Rockwood 1973), its alignment with the radius cannot be ascertained (Marmor and Bechtol 1960). Consequently, it is difficult to distinguish distal epiphyseal separation from elbow dislocation. We report a case in which ultrasonic examination provided good definition of the injury.

\section{CASE REPORT}

Half an hour after the normal birth of a baby girl, it was noticed that she was not moving her right arm. The baby was normal in appearance and no particularly traumatic incident had occurred.

On initial examination the elbow was swollen but not bruised. It was not easy to identify the bony landmarks but the elbow felt unstable in both sagittal and coronal planes. Movement of the elbow appeared to cause some discomfort, but major peripheral nerve injury was excluded by observation of spontaneous movement at the hand and wrist.

Radiographs revealed a "posterior dislocation of the elbow" (Fig. 1) and an arthrogram of the elbow (Roback 1979) performed under general anaesthesia 24 hours

J. J. Dias, FRCS Ed, Lecturer in Orthopaedic Surgery

A. C. LaMont, FRCR, Consultant in Paediatric Radiology

J. M. Jones, FRCS, Consultant in Orthopaedic Surgery

Leicester Royal Infirmary, Infirmary Square, Leicester LEI 5WW, England.

Correspondence should be sent to Mr J. J. Dias.

(C) 1988 British Editorial Society of Bone and Joint Surgery

$0301-620 X / 88 / 5173 \$ 2.00$

$J$ Bone Joint Surg [Br] 1988;70-B:825-8. after birth showed separation of the distal humeral epiphysis with posteromedial displacement. Reduction was difficult, so some posteromedial displacement was accepted and the arm was supported in a collar and cuff.

Ultrasonic examination of both the injured elbow and the contralateral normal elbow was carried out, using the $5 \mathrm{mHz}$ linear array transducer of an Acuson 128 computed sonography system. The elbows were scanned longitudinally along the length of the humerus, first from the posterior aspect (Fig. 2) and next from the lateral side (Fig. 3). The scans confirmed the epiphyseal separation and its displacement. Anterior and medial sections added no further information.

Eight days after birth radiographs showed callus

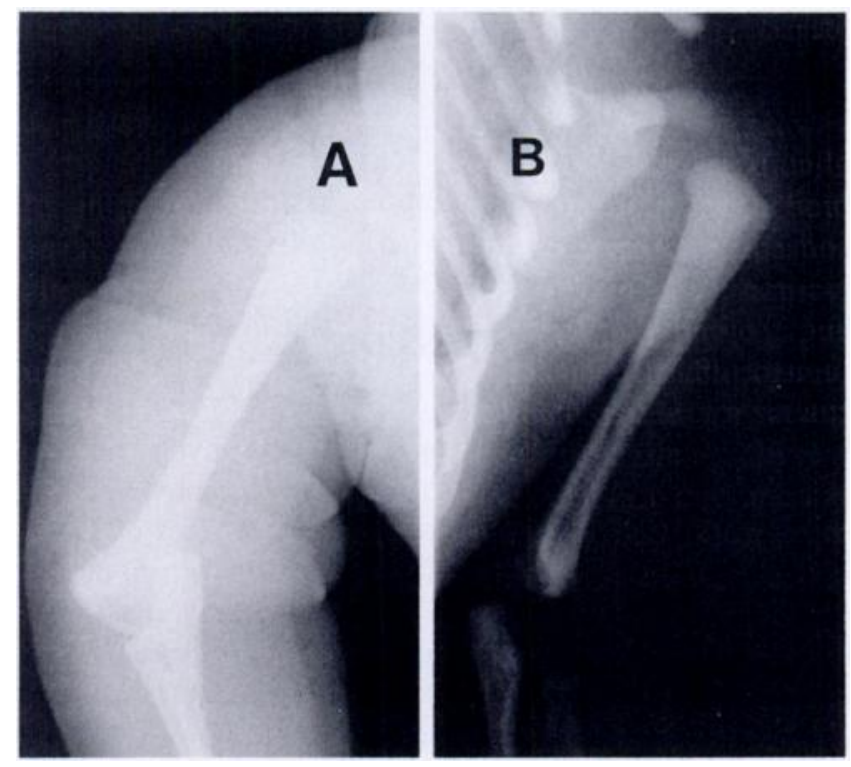

Fig. 1

Radiographs of the injured (A) and contralateral (B) arms. Proximal and medial displacement of the radius and ulna is clearly seen. 

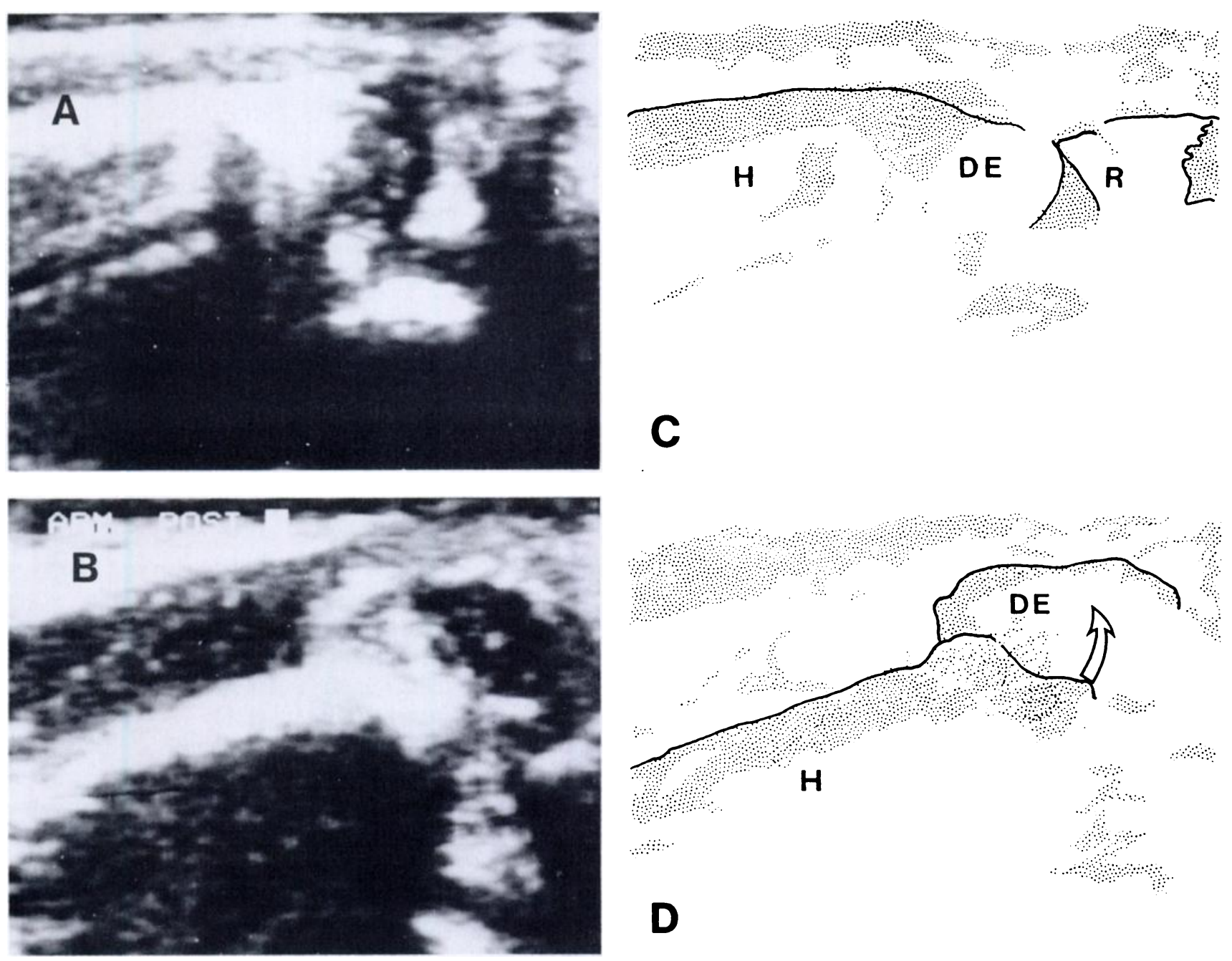

Fig. 2

Posterior sagittal ultrasound section of the normal humerus (A) and the injured humerus (B) with corresponding diagrams (C and D) showing the humerus (H), the distal epiphysis (DE) and the radius (R). On the injured side the distal epiphysis is displaced posteriorly (arrow).

formation around the distal humerus and by four weeks elbow movement was full, with no obvious deformity.

\section{DISCUSSION}

Neonatal separation of the distal epiphysis of the humerus was first reported in 1926 by Camera, and we were able to find only 15 reported cases. Most of these had had complicated births (Table I). Separation of the epiphysis could result from either hyperextension of the elbow or a backward thrust on the forearm with the elbow flexed (Siffert 1963). The displacement of the epiphysis was usually posteromedial, similar to that in older infants and toddlers (Rogers and Rockwood 1973; DeLee et al. 1980; Holda, Manoli and LaMont 1980; Akbarnia et al. 1986). Treatment was by reduction (one open) in 12 cases and without reduction in three.
Posteromedial callus formation was seen in 11 to 15 days. In cases in whom the position was accepted, rapid remodelling left no significant residual deformity.

It might be possible to make the diagnosis on the absence of movement between the olecranon and the two humeral epicondyles when the elbow is stressed in the sagittal plane and the presence of "muffled" crepitus between the metaphysis and the cartilaginous epiphysis (Poland 1898), but these signs may be masked by elbow swelling.

Since the cartilaginous epiphysis is radiolucent, plain radiographs will have the appearance of a posteromedial dislocation of the elbow. Although traumatic neonatal dislocation of the head of the radius (with diagnostic clinical and radiographic findings) has been reported (Schubert 1965; Danielsson and Theander 1981; Bayne and Rang 1984), traumatic dislocation of the elbow at birth has not been documented (Ekengren et 
Table I. Management and outcome in 15 reported cases of neonatal separation of the distal humeral epiphysis

\begin{tabular}{|c|c|c|c|c|c|}
\hline Author & Cases & Injury & Treatment & $\begin{array}{l}\text { Range of } \\
\text { movement }\end{array}$ & Remodelling \\
\hline Siffert 1963 & 3 & $\begin{array}{l}\text { Difficult } \\
\text { labour }\end{array}$ & $\begin{array}{l}\text { Manipulation } \\
\text { Manipulation } \\
\text { Manipulation }\end{array}$ & $\begin{array}{l}\text { Full } \\
\text { Loss of } 10^{\circ} \\
\text { Some loss }\end{array}$ & $\begin{array}{l}\text { Normal } \\
\text { Varus } 10^{\circ} \\
\text { Normal }\end{array}$ \\
\hline Macafee 1967 & 1 & $?$ & Manipulation* & Full & Normal \\
\hline $\begin{array}{l}\text { Mauer, Kolovos } \\
\text { and Loscos } 1967\end{array}$ & 1 & $\begin{array}{l}\text { Difficult } \\
\text { labour }\end{array}$ & Manipulation & $\begin{array}{l}\text { Died at } \\
1 \text { month }\end{array}$ & \\
\hline \multirow{2}{*}{$\begin{array}{l}\text { Ekengren, Bergdahl } \\
\text { and Ekström } 1978\end{array}$} & \multirow[t]{2}{*}{5} & \multirow{2}{*}{$\begin{array}{l}4 \text { difficult } \\
\text { labour } \\
1 \text { none }\end{array}$} & Manipulation & Full & Normal \\
\hline & & & Nil & Full & Normal \\
\hline $\begin{array}{l}\text { Berman and Weiner } \\
1980\end{array}$ & 1 & $\begin{array}{l}\text { Footling } \\
\text { breech } \\
\text { delivery }\end{array}$ & ORIFY & Full & Normal \\
\hline $\begin{array}{l}\text { Downs and Wirth } \\
1982\end{array}$ & 1 & $\begin{array}{l}\text { Footling } \\
\text { breech } \\
\text { delivery }\end{array}$ & Manipulation & $\begin{array}{l}\text { Loss of } 12^{\circ} \\
\text { extension }\end{array}$ & Normal \\
\hline $\begin{array}{l}\text { Akbarnia et al. } \\
1986\end{array}$ & 2 & $\begin{array}{l}\text { Birth } \\
\text { trauma }\end{array}$ & $\begin{array}{l}\mathrm{Nil} \\
\mathrm{Nil}\end{array}$ & $\begin{array}{l}\text { Full } \\
\text { Full }\end{array}$ & $\begin{array}{l}\text { Normal } \\
\text { Normal }\end{array}$ \\
\hline $\begin{array}{l}\text { Dias, LaMont } \\
\text { and Jones } 1988\end{array}$ & 1 & None & Manipulation & Full & \\
\hline
\end{tabular}

* under general anaesthesia

topen reduction and internal fixation
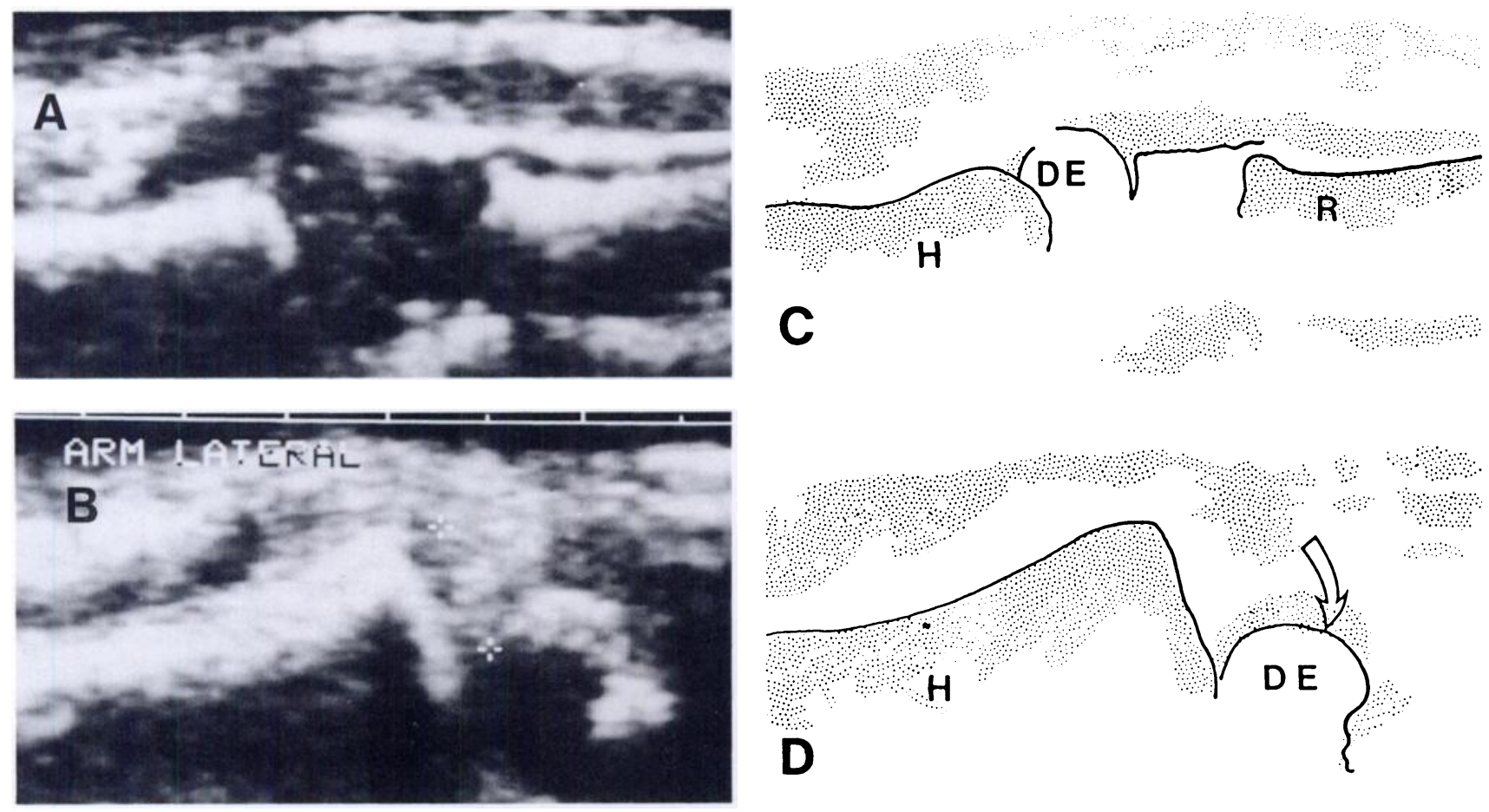

Fig. 3

Lateral coronal ultrasound section of the normal humerus (A) and the injured humerus (B) with corresponding diagrams (C and D). On the injured side the distal epiphysis is displaced medially (arrow). 
al. 1978). The most likely diagnosis on plain radiography must therefore be epiphyseal separation.

This diagnosis may be suggested by a decrease in the distance between the distal humerus and the proximal radius and ulna, compared to that on the contralateral side (Siffert 1963). Elbow arthrography, which defines the cartilaginous epiphysis (Hansen, Barnes and Tullos 1982; Akbarnia et al. 1986), can demonstrate the injury, but this is an invasive investigation which has some attendant risks.

Ultrasonic examination is non-invasive and can easily be performed on a neonate. It can provide clear definition of the cartilaginous epiphysis, establish the diagnosis and record the direction and the magnitude of displacement. It will also allow continued monitoring during the healing phase. A good outcome can be anticipated regardless of the method of treatment (Table I), but ultrasonic examination avoids the risks of arthrography and of anaesthesia at this vulnerable age.

No benefits in any form have been received or will be received from a commercial party related directly or indirectly to the subject of this article.

\section{REFERENCES}

Akbamia BA, Silberstein MJ, Rende RJ, Graviss ER, Luisiri A. Arthrography in the diagnosis of fractures of the distal end of the humerus in infants. J Bone Joint Surg [Am] 1986;68-A :599-602.

Bayne O, Rang M. Medial dislocation of the radial head, following breech delivery: a case report and review of the literature. $J$ Pediatr Orthop 1984;4:485-7.
Berman JM, Weiner DS. Neonatal fracture-separation of the distal humeral chondroepiphysis: a case report. Orthopedics $1980 ; 3: 875-9$.

Camera U. Total, pure, traumatic detachment of inferior humeral epiphysis. Chir d. Org di Movemento 1926;294-316.

Danielsson L, Theander G. Traumatic dislocation of the radial head at birth. Acta Radiol [Diagn] (Stockh) 1981 ;22(3B):379-82.

DeLee JC, Wilkins KE, Rogers LF, Rockwood CA. Fracture-separation of the distal humeral epiphysis. J Bone Joint Surg [Am] $1980 ; 62-A: 46-51$.

Downs DM, Wirth CR. Fracture of the distal humeral chondroepiphysis in the neonate: a case report. Clin Orthop 1982;169:155-8.

Ekengren K, Bergdahl S, Ekström G. Birth injuries to the epiphyseal cartilage. Acta Radiol [Diagn] (Stockh) 1978;19:197-204.

Hansen PE, Barnes DA, Tullos HS. Arthrographic diagnosis of an injury pattern in the distal humerus of an infant. J Pediatr Orthop $1982 ; 2: 569-72$.

Holda ME, Manoli A II, LaMont RL. Epiphyseal separation of the distal end of the humerus with medial displacement. $J$ Bone Joint Surg [Am] 1980;61-A:52-7.

Macafee AL. Infantile supracondylar fracture. J Bone Joint Surg [Br] 1967;49-B:768-70.

Marmor L, Bechtol CO. Fracture separation of the lower humeral epiphysis: report of a case. J Bone Joint Surg [Am] $1960 ; 42-A: 333-6$.

Mauer I, Kolovos D, Loscos R. Epiphysiolysis of the distal humerus in a newborn. Bull Hosp Joint Dis 1967;18:109-18.

Poland J. Traumatic separation of the epiphyses. London: Smith \& Elder, 1898

Roback DL. Elbow arthrography: brief technical considerations. Clin Radiol 1979;30:311-2.

Rogers LF, Rockwood CA Jr. Separation of the entire distal humeral epiphysis. Radiology 1973;106:393-400.

Schubert JJ. Dislocation of the radial head in the newborn infant : case report and review of the literature. J Bone Joint Surg [Am] $1965 ; 47-A$ : $1019-23$.

Siffert RS. Displacement of the distal humeral epiphysis in the newborn. J Bone Joint Surg [Am] 1963;45-A : 165-9. 